Pacific Journal of Mathematic 


\section{OSCILLATION THEOREMS FOR SECOND ORDER LINEAR DIFFERENTIAL EQUATIONS}

\section{LYNN ERBE}

It is the purpose of this paper to show that oscillation of the linear second order equation

$$
\left(r(t) x^{\prime}\right)^{\prime}+p(t) x=0
$$

implies oscillation of the equation

$$
\left(r_{1}(t) x^{\prime}\right)^{\prime}+a(t) p_{1}(t) x=0
$$

for a large class of positive functions $a(t)$, where the following condition holds for all large $t$ :

$$
r(t) \geqq r_{1}(t)>0, p(t) \leqq p_{1}(t) \text {. }
$$

We shall also assume that the functions $r(t), \boldsymbol{r}_{1}(t), p(t), p_{1}(t)$, and $a(t)$ are continuous on some half line $[T,+\infty)$.

Recently, Fink and St. Mary [2] have shown that to each $p(t) \in C[T,+\infty)$ one can associate a number $\lambda_{0}, 0 \leqq \lambda_{0} \leqq+\infty$, such that the equation $\left(r x^{\prime}\right)^{\prime}+\lambda p x=0$ is oscillatory provided the number $\lambda$ satisfies $\lambda>\lambda_{0}$ and nonoscillatory if $0 \leqq \lambda<\lambda_{0}$. We shall show that $\lambda$ may be replaced by a class of positive functions $a(t)$. Thus, one may associate with each $p(t)$ a wide class of functions which are oscillation preserving. For an extensive bibliography concerning oscillation and nonoscillation criteria for (1) we refer the reader to [4]. We wish to remark that results obtained here are immediate consequences of the Sturm Comparison Theorem if $p(t)$ and $p_{1}(t)$ are nonnegative. (See [3]).

We begin with a comparison theorem on a finite interval $[c, d]$.

THEOREM 1.1 Let $a(t) \in C^{(1)}[c, d]$ satisfy $a(t) \geqq 1$ and $a^{\prime}(t) \geqq 0$ on $[c, d]$ and assume condition $(\mathrm{H})$ holds on $[c, d]$. Let $y(t)$ and $z(t)$ be solutions of (1) and (2), respectively, with

$$
\frac{r(c) y^{\prime}(c)}{y(c)} \geqq \frac{r_{1}(c) z^{\prime}(c)}{z(c)}>0
$$

and assume $y^{\prime}(d)=0$ with $y^{\prime}(t)>0$ on $[c, d)$. Then $z^{\prime}\left(t_{0}\right)=0$ for some $c<t_{0} \leqq d$.

Proof. We remark first that the expression on the right [left] of (3) is to be replaced by $+\infty$ in case $z(c)=0[y(c)=0]$. Assume 
first that $r \equiv r_{1}$ and $p \equiv p_{1}$ on $[c, d]$ and that equality holds in (3). If the lemma is not true, we may assume $z^{\prime}(t)>0$ on $(c, d]$. We have

$$
\begin{aligned}
0 \leqq & \int_{c}^{d} r(t)(a(t)-1)\left(y^{\prime}(t)\right)^{2} d t \\
= & -r(c) y(c) y^{\prime}(c)(a(c)-1)+\int_{c}^{d} p(t)(y(t))^{2}(a(t)-1) d t \\
& -\int_{c}^{d} r(t) y(t) y^{\prime}(t) a^{\prime}(t) d t \leqq \int_{c}^{d} p(t)(y(t))^{2}(a(t)-1) d t
\end{aligned}
$$

since $r(t) y(t) y^{\prime}(t) a^{\prime}(t) \geqq 0$ on $[c, d]$.

Now letting $w(t)=r(t)\left(z(t) y^{\prime}(t)-y(t) z^{\prime}(t)\right)$ we have

$$
\begin{aligned}
& \int_{c}^{d} p(t)(y(t))^{2}(a(t)-1) d t=\int_{c}^{d} w^{\prime}(t) y(t) / z(t) d t \\
& \quad=-r(d)(y(d))^{2} z^{\prime}(d) / z(d)-\int_{c}^{d}(w(t))^{2} / r(t)(z(t))^{2} d t<0,
\end{aligned}
$$

and this is a contradiction. Now to extend the result to the case $r(t) \geqq r_{1}(t)>0$ and $p(t) \leqq p_{1}(t)$, consider the equations

$$
\begin{gathered}
\left(r(t) z^{\prime}\right)^{\prime}+a(t) p(t) z=0 \\
\left(r_{1}(t) u^{\prime}\right)^{\prime}+a(t) p_{1}(t) u=0
\end{gathered}
$$

and let $z(t), u(t)$ be the solutions of (4) and (5), respectively, satisfying $z^{\prime}(t)>0$ on $[c, d), z^{\prime}(d)=0$ and

$$
\frac{r(c) z^{\prime}(c)}{z(c)} \geqq \frac{r_{1}(c) u^{\prime}(c)}{u(c)}>0 .
$$

Suppose that $u^{\prime}(t)>0$ on $(c, d]$. Then multiplying (4) by $u(t)$ and (5) by $z(t)$, integrating, and subtracting yields

$$
\begin{aligned}
& r_{1}(d) u^{\prime}(d) z(d)+r(c) z^{\prime}(c) u(c)-r_{1}(c) u^{\prime}(c) z(c) \\
& +\int_{c}^{d}\left(r(t)-r_{1}(t)\right) u^{\prime}(t) z^{\prime}(t) d t+\int_{c}^{d} a(t) z(t) u(t)\left(p_{1}(t)-p(t)\right) d t=0,
\end{aligned}
$$

which is a contradiction since the left hand side of (6) is positive. Therefore, $u^{\prime}\left(t_{0}\right)=0$ for some $c<t_{0} \leqq d$. This proves the theorem.

We now introduce the following definition:

Condition (A). The function $\theta(t) \in C[T,+\infty)$ is said to satisfy condition (A) provided

$$
\lim _{t \rightarrow \infty} \inf \int_{T}^{t} \theta(s) d s \geqq 0 \text { for all large } T .
$$


Lemma 1.2. Assume $p(t)$ satisfies condition (A) and let $\int^{\infty} d s / r(s)=$ $+\infty$. Let $y(t)$ be a solution of $(1)$ with $y(t)>0$ for all $t \geqq t_{0}$. Then there is a $t_{1} \geqq t_{0}$ such that $y^{\prime}(t)>0$ on $\left[t_{1},+\infty\right)$ or $y^{\prime} \equiv 0$ for all large $t$.

Proof. Assume $y^{\prime} \neq 0$ for all large $t$. If the lemma is not true, assume first that $y^{\prime}(t)<0$ for all $t \geqq T, T \geqq t_{0}$. We may assume by condition (A) that $T$ is sufficiently large so that

$$
\int_{T}^{t} p(s) d s \geqq 0 \text { for all } t \geqq T \text {. }
$$

For if no such $T$ exists, let $T \geqq t_{0}$ be fixed but arbitrary and define

$$
T_{1}=\sup \left\{t>T: \int_{T}^{t} p(s) d s<0\right\}
$$

Now if $T_{1}=+\infty$, then choose $t_{n} \rightarrow+\infty$ such that

$$
\int_{T}^{t_{n}} p(s) d s<0 \text { for all } n \text {. }
$$

This contradicts the assumption that $p(t)$ satisfies condition (A) by the arbitrariness of $T$. Hence, $T_{1}<+\infty$ which implies

$$
\int_{T_{1}}^{t} p(s) d s \geqq 0 \text { for all } t \geqq T_{1} \text {, }
$$

contradicting the assumption that no such $T_{1}$ exists. Then

$$
\int_{T}^{t} p(s) y(s) d s=y(t) \int_{T}^{t} p(s)-\int_{T}^{t} y^{\prime}(s) \int_{T}^{s} p(\sigma) d \sigma d s \geqq 0, t \geqq T,
$$

so that integrating (1) we have by (7)

$$
y^{\prime}(t) \leqq r(T) y^{\prime}(T) / r(t), t \geqq T .
$$

Now an integration of (8) for $t \geqq T$ shows that $y(t) \rightarrow-\infty$, a contradiction.

Assume next that $y^{\prime}\left(T_{n}\right)=0$ for $T_{n} \rightarrow+\infty$. Let $v(t)=-r(t) y^{\prime}(t) / y(t)$, $t \geqq t_{0}$ so that

$$
v^{\prime}(t)=p(t)+(v(t))^{2} / r(t), t \geqq t_{0} .
$$

Integrating (9) between $T_{n}$ and $T_{n+1}$, summing on $n$, and using the fact that $v(t) \neq 0$ for all large $t$ contradicts the assumption that $p(t)$ satisfies condition (A). This proves the lemma.

THEOREM 1.3. Let equation (1) be oscillatory and assume condi- 
tion $(\mathrm{H})$ holds for all large $t$. Let $a(t) \in C^{(1)}[T,+\infty)$ satisfy $a(t) \geqq 1$ and $a^{\prime}(t) \geqq 0$ for $t \geqq T$ and let $a(t) p_{1}(t)$ satisfy condition (A). Assume also that $\int^{\infty} d s / r_{1}(s)=+\infty$. Then equation (2) is oscillatory.

Proof. If equation (2) is nonoscillatory, we may assume that $z(t)$ is a solution of (2) with $z(t)>0$ and $z^{\prime}(t)>0$ for $t \geqq T$. Otherwise, if $z^{\prime} \equiv 0$ for all large $t$, then $p_{1} \equiv 0$ for all large $t$ so (1) cannot be oscillatory by the Sturm Comparison Theorem. But if $y(t)$ is a solution of (1) with $y\left(t_{1}\right)=y^{\prime}\left(t_{2}\right)=0, t_{2}>t_{1} \geqq T$ and $y^{\prime}(t)>0$ on $\left[t_{1}, t_{2}\right)$, then $z^{\prime}(t)$ must vanish on $\left(t_{1}, t_{2}\right]$ by Theorem 1.1, a contradiction.

CoROLLARY 1.4. Let equation (1) be nonoscillatory, let $p(t)$ satisfy condition (A), and let $a(t) \in C^{(1)}[T,+\infty), r_{1}(t), p_{1}(t), r(t), p(t)$ satisfy the following conditions for all $t \geqq T$ :

$$
0<a(t) \leqq 1, a^{\prime}(t) \leqq 0, r(t) \leqq r_{1}(t), p_{1}(t) \leqq p(t)
$$

and assume $\int^{\infty} d s / r(s)=+\infty$. Then equation (2) is nonoscillatory.

Proof. If $y(t)$ is a nonoscillatory solution of (1) with $y(t)>0$ for $t \geqq T$ and $y^{\prime} \equiv 0$ for all large $t$, then $p(t) \equiv 0$ for all large $t$ so the result follows from the Sturm Comparison Theorem. If $y^{\prime} \neq 0$ for all large $t$ then a proof similar to Theorem 1.3 is valid (using the analogue of Theorem 1.1).

EXAMPLE 1.5. Willett [5] has shown that

$$
x^{\prime \prime}+\lambda\left((2+t \sin t) / 2 t^{2}\right) x=0
$$

is oscillatory if $\lambda>\sqrt{18}-4$ and nonoscillatory if $\lambda<\sqrt{18}-4$. Since $p(t)=(2+t \sin t) / 2 t^{2}$ satisfies condition (A) we see that with $a(t)=$ $1 /(t+\sin t)$,

$$
x^{\prime \prime}+\gamma a(t) p(t) x=0
$$

is nonoscillatory for all $\gamma \geqq 0$.

REMARK. The differentiability assumptions on $a(t)$ can be replaced by nonincreasing or nondecreasing in the previous results. We wish also to remark that techniques similar to the above may be used to obtain oscillation and boundedness results for the second order nonlinear equation

$$
x^{\prime \prime}+p(t) x^{2 n+1}=0
$$


and its generalizations under the assumption that $p(t)$ satisfies condition (A) (see [1]).

2. In this section we shall weaken the assumptions on $p(t)$ and strengthen the assumptions on $a(t)$ and $r_{1}(t)$. We begin with a comparison theorem on a finite interval.

THEOREM 2.1. Let $y(t)$ be a nonnull solution of (1) satisfying $y(c)=y(d)=0$, let $a(t) \in C^{(1)}[c, d]$ satisfy $a(t) \geqq 1$ on $[c, d]$ and assume $r_{1}(t) a^{\prime}(t)$ is nonincreasing on $[c, d]$. Assume also that condition $(\mathrm{H})$ holds on $[c, d]$. Then every solution of (2) has a zero on $(c, d)$.

Proof. We may assume $p \equiv p_{1}$ and $r \equiv r_{1}$ on $[c, d]$ since the solution to $\left(r_{1}(t) x^{\prime}\right)^{\prime}+p_{1}(t) x=0$ satisfying $x(c)=0 \neq x^{\prime}(c)$ must vanish again on $(c, d]$ by the Sturm Comparison Theorem. Let $z(t)$ be the solution of (2) satisfying $z(c)=0 \neq z^{\prime}(c)$ and assume $z(t)>0$ on $(c, d]$. Then we have

$$
\begin{aligned}
0 \leqq & \int_{c}^{d} r(t)(a(t)-1)\left(y^{\prime}(t)\right)^{2} d t=\int_{c}^{d} p(t)(y(t))^{2}(a(t)-1) d t \\
& -\int_{c}^{d} r(t) a^{\prime}(t) y(t) y^{\prime}(t) d t \\
= & \int_{c}^{d} p(t)(y(t))^{2}(a(t)-1) d t+\frac{1}{2} \int_{c}^{d}(y(t))^{2} d\left(r(t) a^{\prime}(t)\right) \\
\leqq & \int_{c}^{d} p(t)(y(t))^{2}(a(t)-1) d t .
\end{aligned}
$$

This leads to a contradiction by an argument similar to Theorem 1.1 and proves the result.

CoROLlaRy 2.2. Assume equation (1) is oscillatory and for all $t \geqq T$ assume that $a(t) \in C^{(1)}[T,+\infty)$ satisfies $a(t) \geqq 1$ with $r_{1}(t) a^{\prime}(t)$ nonincreasing. Let condition $(\mathrm{H})$ hold for all $t \geqq T$. Then equation (2) is oscillatory.

CoRollary 2.3. Assume equation (1) is oscillatory and let $\left\{a_{n}(t)\right\}_{n=1}^{\infty}$ and $\left\{r_{n}(t)\right\}_{n=1}^{\infty}$ be a sequence of continuous functions with $a_{n}(t) \in C^{(1)}[T,+\infty), a_{n}(t) \geqq 1, r_{n}(t) a_{n}^{\prime}(t)$ nonincreasing, and $r(t) \geqq r_{1}(t) \geqq$ $\cdots \geqq r_{n}(t) \geqq \cdots>0$ for all $t \geqq T$.

Let

$$
\lim _{n \rightarrow \infty} r_{n}(t) \equiv r_{0}(t)>0
$$

and

$$
\lim _{n \rightarrow \infty} \prod_{i=1}^{n} a_{i}(t) \equiv a(t)
$$


where we assume the convergence is uniform on compact subsets of $[T,+\infty)$. Then the equation

$$
\left(r_{0}(t) x^{\prime}\right)^{\prime}+a(t) p(t) x=0
$$

is oscillatory.

Analogous results are true for the case when (1) is nonoscillatory:

COROLLARY 2.4. Let (1) be disconjugate on the interval $[c, d]$. (That is, the only solution of (1) with more than one zero on $[c, d]$ is the zero solution.) Let $a(t) \in C^{(1)}[c, d]$ satisfy $0<a(t) \leqq 1$ and assume $r_{1}(t) a^{\prime}(t) /(a(t))^{2}$ is nondecreasing. Let $r(t) \leqq r_{1}(t)$ and $p(t) \geqq p_{1}(t)$ on $[c, d]$. Then equation (2) is disconjugate on $[c, d]$.

EXAMPLE 2.5. Let $r(t) \equiv r_{1}(t) \equiv 1$ and assume $x^{\prime \prime}+p(t) x=0$ is oscillatory. Then

$$
x^{\prime \prime}+t^{\alpha}(\log t)^{\beta} p(t) x=0
$$

is oscillatory for all $\alpha, \beta \geqq 0$.

In a certain sense, the conditions imposed on $a(t)$ in Theorem 2.1 and the following corollaries cannot be weakened. For example, if $p \equiv p_{1}$ is positive on $[c, d]$ and $r \equiv r_{1} \equiv 1$, then using the ordinary Sturm Comparison Theorem with $a(t) \equiv 1$ on some subinterval $\left[c, t_{0}\right]$, $c<t_{0}<d, a(d)<1$, and $a^{\prime \prime}(t) \leqq 0$ on $[c, d]$, we see that equation (2) oscillates slower than equation (1).

To show the necessity of the requirement that $r_{1}(t) a^{\prime}(t)$ be nonincreasing in the above results is less trivial. To do this, we appeal to some recent results announced by Wong [6], where it is shown that

$$
x^{\prime \prime}+\left(\frac{(\log t-1) \sin \sqrt{2 t}}{t \log t}\right) x=0
$$

is oscillatory. However, it is also shown in [6] that

$$
x^{\prime \prime}+\left(\frac{\sin \sqrt{2 t}}{t}\right) x=0
$$

is nonoscillatory. Here, with $a(t)=(\log t)(\log t-1)^{-1}$, all the assumptions, except for $a^{\prime}(t)$ nonincreasing, of Corollary 2.2 are satisfied. Yet the conclusion of Corollary 2.2 does not hold for this example.

\section{REFERENCES}

1. L. Erbe, Oscillation theorems for second order nonlinear differential equations, Proc. Amer. Math. Soc. 24 (1970), 811-814. 
2. A. M. Fink and D.F. St. Mary, A generalized Sturm comparison theorem and oscillation coefficients, Mh. Math. 73 (1969), 207-212.

3. P. Hartman, Ordinary Differential Equations, Wiley, New York, 1964.

4. D. Willett, Classification of second order linear differential equations with respect to oscillation, Advances in Mathematics 3 (1969), 594-623.

5. - On the oscillatory behavior of the solutions of second order linear differential equations, Ann. Polon. Math. 21 (1969), 175-194.

6. J. S. W. Wong, Second order linear oscillation with integrable coefficients, Bull. Amer. Math. Soc. 74 (1968), 909-911.

Received October 15, 1969. This research was supported by a University of Alberta Post-doctoral Fellowship.

UNIVERSITY OF ALBERTA

Edmonton, Alberta

CANADA 



\section{PACIFIC JOURNAL OF MATHEMATICS}

\section{EDITORS}

\author{
H. SAMELSON \\ Stanford University \\ Stanford, California 94305

\section{Richard Pierce} \\ University of Washington \\ Seattle, Washington 98105
}

J. DugundJI

Department of Mathematics

University of Southern California

Los Angeles, California 90007

RichaRd ARENS

University of California

Los Angeles, California 90024

\section{ASSOCIATE EDITORS}
E. F. BECKENBACH
B. H. NeUMANN
F. WOLE
K. YoshidA

\section{SUPPORTING INSTITUTIONS}

\author{
UNIVERSITY OF BRITISH COLUMBIA \\ CALIFORNIA INSTITUTE OF TECHNOLOGY \\ UNIVERSITY OF CALIFORNIA \\ MONTANA STATE UNIVERSITY \\ UNIVERSITY OF NEVADA \\ NEW MEXICO STATE UNIVERSITY \\ OREGON STATE UNIVERSITY \\ UNIVERSITY OF OREGON \\ OSAKA UNIVERSITY \\ UNIVERSITY OF SOUTHERN CALIFORNIA
}

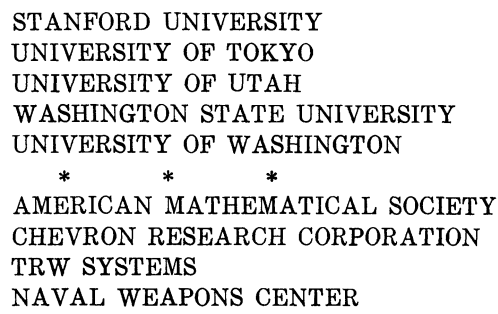

The Supporting Institutions listed above contribute to the cost of publication of this Journal, but they are not owners or publishers and have no responsibility for its content or policies.

Mathematical papers intended for publication in the Pacific Journal of Mathematics should be in typed form or offset-reproduced, (not dittoed), double spaced with large margins. Underline Greek letters in red, German in green, and script in blue. The first paragraph or two must be capable of being used separately as a synopsis of the entire paper. The editorial "we" must not be used in the synopsis, and items of the bibliography should not be cited there unless absolutely necessary, in which case they must be identified by author and Journal, rather than by item number. Manuscripts, in duplicate if possible, may be sent to any one of the four editors. Please classify according to the scheme of Math. Rev. Index to Vol. 39. All other communications to the editors should be addressed to the managing editor, Richard Arens, University of California, Los Angeles, California, 90024.

50 reprints are provided free for each article; additional copies may be obtained at cost in multiples of 50 .

The Pacific Journal of Mathematics is published monthly. Effective with Volume 16 the price per volume (3 numbers) is $\$ 8.00$; single issues, $\$ 3.00$. Special price for current issues to individual faculty members of supporting institutions and to individual members of the American Mathematical Society: $\$ 4.00$ per volume; single issues $\$ 1.50$. Back numbers are available.

Subscriptions, orders for back numbers, and changes of address should be sent to Pacific Journal of Mathematics, 103 Highland Boulevard, Berkeley, California, 94708.

PUBLISHED BY PACIFIC JOURNAL OF MATHEMATICS, A NON-PROFIT CORPORATION

Printed at Kokusai Bunken Insatsusha (International Academic Printing Co., Ltd.), 7-17, Fuj̣imi 2-chome, Chiyoda-ku, Tokyo, Japan. 


\section{Pacific Journal of Mathematics}

\section{Vol. 35, No. $2 \quad$ October, 1970}

Valentin Danilovich Belousov and Palaniappan L. Kannappan, Generalized Bol functional equation .................................... 259

Charles Morgan Biles, Gelfand and Wallman-type compactifications ........... 267

Louis Harvey Blake, A generalization of martingales and two consequent convergence theorems .................................... 279

Dennis K. Burke, On p-spaces and $w \Delta$-spaces..................... 285

John Ben Butler, Jr., Almost smooth perturbations of self-adjoint operators . . . . . . 297

Michael James Cambern, Isomorphisms of $C_{0}(Y)$ onto $C(X) \ldots \ldots \ldots \ldots \ldots . \ldots 307$

David Edwin Cook, A conditionally compact point set with noncompact closure ... 313

Timothy Edwin Cramer, Countable Boolean algebras as subalgebras and homomorphs .........................................

John R. Edwards and Stanley G. Wayment, A v-integral representation for linear operators on spaces of continuous functions with values in topological vector spaces.............................................

Mary Rodriguez Embry, Similarities involving normal operators on Hilbert

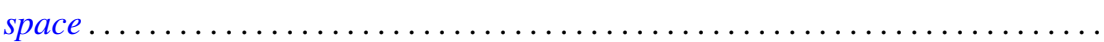

Lynn Harry Erbe, Oscillation theorems for second order linear differential

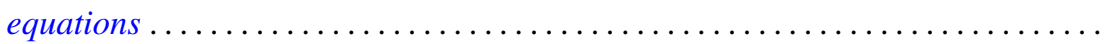

William James Firey, Local behaviour of area functions of convex bodies .......... Joe Wayne Fisher, The primary decomposition theory for modules ..............

Gerald Seymour Garfinkel, Generic splitting algebras for Pic ..................

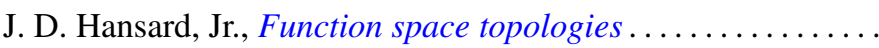

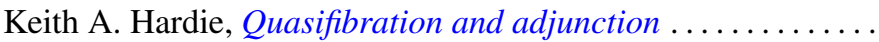

G. Hochschild, Coverings of pro-affine algebraic groups ...........

Gerald L. Itzkowitz, On nets of contractive maps in uniform spaces ..

381

389

399

417

Melven Robert Krom and Myren Laurance Krom, Groups with free nonabelian subgroups....................................

James Robert Kuttler, Upper and lower bounds for eigenvalues by finite differences ......................................

Dany Leviatan, A new approach to representation theory for convolution transforms . . .

Richard Beech Mansfield, Perfect subsets of definable sets of real numbers ...

Brenda MacGibbon, A necessary and sufficient condition for the embedding of a

Lindelof space in a Hausdorff $\mathscr{H} \sigma$ space ..................

David G. Mead and B. D. McLemore, Ritt's question on the Wronskian ....

Edward Yoshio Mikami, Focal points in a control problem .....

Paul G. Miller, Characterizing the distributions of three independent n-dimensional random variables, $X_{1}, X_{2}, X_{3}$, having analytic characteristic functions by the joint distribution of $\left(X_{1}+X_{3}, X_{2}+X_{3}\right)$. . .

P. Rosenthal, On the Bergman integral operator for an elliptic partial differential equation with a singular coefficient....

Douglas B. Smith, On the number of finitely generated $O$-group 